\title{
Optimization of bonding parameters of laminated wood using a novel bio-based RPF adhesive
}

\author{
Xueyong Ren ${ }^{1, *}$, Yinlan Shen $^{2}$, Ying Gao ${ }^{1}$, Derong Zhang ${ }^{1}$, and Jianmin Chang ${ }^{1}$ \\ ${ }^{1}$ MOE Key Laboratory of Wooden Material Science and Application, College of Materials Science and Technology, Beijing Forestry \\ University, Beijing 100083, China \\ ${ }^{2}$ Civil engineering Department, College of Architecture and Civil Engineering, Beijing University of Technology, Beijing 100124, \\ China
}

\begin{abstract}
Adhesive is the key component and factor for the manufacture of glulam, affected both the properties and cost of glulam product. Bio-based resorcinol-phenol-formaldehyde (BRPF) resin was developed by partly replacing the expensive resorcinol and phenol with the cheap biomass derived pyrolysis oil. The press process parameters and the dosage of adhesive and corresponding curing agent were selected as the factors and extensively studied. BRPF resin was successfully used to bond the laminas to produce glulam, and the optimized process parameters for the cold-pressing adhesion of BRPF resin with pine wood were obtained as follows: the cold-pressing pressure $1.4 \mathrm{MPa}$, the cold-pressing time $9 \mathrm{~h}$, the amount of adhesive coating $320 \mathrm{~g} / \mathrm{m}^{2}$, and the proportion of curing agent (poly-formaldehyde) $17 \%$. The mechanical performances of laminated wood bonding with BRPF resin under the optimal condition were further verified. It is believed that the results obtained here will promote the use of bio-based resin in the bonding of laminated wood, and then contribute to the green manufacturing of glulam with lower cost.
\end{abstract}

\section{Introduction}

Wood is the only naturally renewable and green building material, and being used in many areas of light construction for long time as its simplicity in fabrication, lightness, and environmental compatibility, etc [1]. Modern technology has increased the durability and application of wood, spurred a host of new engineered wooden product, such as glulam, CLT, LVL, etc. Glulam (glued laminated timber) is a structural wood composite manufactured by gluing individual smaller pieces of wood together using adhesives. Adhesively bonding of timber structural elements provides new opportunities as it is well adapted for the anisotropic and fibrous nature of the material.

In general, the common adhesives for the glulam are resorcinol formaldehyde (RF) resin, phenol-RF (PRF) resin, and aqueous polymer-isocyanate (API) adhesive, and melamine-urea-formaldehyde-based honeymoon adhesive [2-4]. With the increased interest in the use of renewable material to substitute fossil-based ingredients, some biomass based adhesives have been developed for glulam.

Using castor oil-based polyurethane adhesive is viable in the manufacture of glued laminated timber from the standpoint of structural performance [5]. Whey protein-based aqueous polymer-isocyanate adhesive were developed and using in the preparation of glulam. It was concluded that [6] addition of crosslinker polymeric methylene bisphenyl diisocyanate (p-MDI) not only increased the cohesive strength of the cured adhesive by crosslinking whey proteins but also resulted in strong chemical bonds via urethane linkage in wood bond-lines. Shear strength tested were conducted on both untreated and heat-treated wood with several kinds of adhesive, such as phenol formaldehyde (PF), melamine urea formaldehyde (MUF), melamine formaldehyde (MF), and polyurethane (PUR), and the result [7] showed that these adhesives performed in a rather similar way and fulfilled the required value for shear strength of bond.

Besides, the influence of selected wood properties, manufacturing conditions, and the effect of a hydromethylated resorcinol primer on the delamination resistance of beech glulam bonded under laboratory and industrial conditions with a melamine urea formaldehyde adhesive were investigated. The results [8] indicated that bond durability required for service class 1 can be attained by restricting lamella thickness in beech glulam to a maximum of $30 \mathrm{~mm}$ and by using a minimum closed assembly time of $40 \mathrm{~min}$.

Pyrolysis bio-oil is produced by the fast pyrolysis of renewable biomass resources [9], which contains many chemical-active compounds, such as phenols, aldehydes, esters, etc. Pyrolysis oil was also used to react with resorcinol, phenol, and formaldehyde to produce coldsetting adhesive for glulam [10], which reduces the cost of adhesive by replacing the expensive resorcinol and phenol with the cheap bio-oil.

Pyrolysis oil-based resorcinol-phenol-formaldehyde resin is a new adhesive for glulam, and further

\footnotetext{
* Corresponding author: rxueyong@bjifu.edu.cn
} 
investigations into the bonding process parameters are required. Therefore, the objective of the present study is to research and optimize the press process parameters and the dosage of adhesive and corresponding curing agent, which will help to promote the use of bio-based structural adhesive in glulam.

\section{Materials and Methods}

\subsection{Materials}

Bio-based phenol resorcinol formaldehyde (BPRF) adhesive was synthesized with a green and renewable materials, pyrolytic oil (bio-oil) produced from the fast pyrolysis of biomass waste.

Pine wood (Pinus sylvestris var. mongolica Litv.), collected from Greater Khingan Mountains, Heilongjiang Province, was used as the feedstock to produce the glulam.

The resorcinol, phenol, formaldehyde, sodium hydroxide, and polyformaldehyde were reagent grade and used as obtained.

\subsection{Method for experimental design}

Cold-pressure, time, amount of adhesive coating and proportion of curing agent were selected as experimental factors in this experiment. Single factor experiment was design and conducted to explore the impact of each individual factor on the bonding strength, as shown in Table 1. Verification experiments were also performed to obtain the optimized parameters for the bonding process with bio-based RPF adhesive.

Table 1. Single factor experimental design scheme

\begin{tabular}{|c|c|c|c|c|}
\hline $\begin{array}{c}\text { Level } \\
\text { of } \\
\text { factor }\end{array}$ & $\begin{array}{c}\text { Pressure } \\
(\mathrm{Mpa})\end{array}$ & $\begin{array}{c}\text { Time } \\
(\mathrm{h})\end{array}$ & $\begin{array}{c}\text { Amount of } \\
\text { adhesive coating } \\
\left(\mathrm{g} / \mathrm{m}^{2}\right)\end{array}$ & $\begin{array}{c}\text { Proportion } \\
\text { of curing } \\
\text { agent }(\%)\end{array}$ \\
\hline 1 & $\mathbf{0 . 8}$ & $\mathbf{6}$ & $\mathbf{2 0 0}$ & $\mathbf{1 1}$ \\
\hline 2 & $\mathbf{1 . 0}$ & $\mathbf{7}$ & $\mathbf{2 4 0}$ & $\mathbf{1 3}$ \\
\hline 3 & $\mathbf{1 . 2}$ & $\mathbf{8}$ & $\mathbf{2 8 0}$ & $\mathbf{1 5}$ \\
\hline 4 & $\mathbf{1 . 4}$ & $\mathbf{9}$ & $\mathbf{3 2 0}$ & $\mathbf{1 7}$ \\
\hline 5 & $\mathbf{1 . 6}$ & $\mathbf{1 0}$ & $\mathbf{3 6 0}$ & $\mathbf{1 9}$ \\
\hline
\end{tabular}

\subsection{Method for the preparation of glulam}

Glulam samples (Figure 2) bonded by RF and BRF resin were prepared to test the bonding performance by the following procedures. Pine wood with a moisture content of $12 \%$ was used as the raw material for glulam.

I. At first, the pine wood was cut into blocks following the grain direction with a dimension of 55 $\mathrm{mm} \times 50 \mathrm{~mm} \times 20 \mathrm{~mm}$. The blocks were polished by sand paper and used within 24 hours.

II. Then, $11-19 \%$ fine paraformaldehyde powder (200 mesh) as hardener was added into the BRPF resin and mixed well to prepare the final adhesives.

III. Next, the final adhesive mixture was spread on the surface of pine wood blocks with a dosage of 200$360 \mathrm{~g} / \mathrm{m}^{2}$ and displayed for 15 minutes. The temperature in the surroundings of working labs was adjusted as $23{ }^{\circ} \mathrm{C}$.

IV. Finally, two pine wood blocks were assembled together under a pressure of 0.8-1.6 MPa for 6-10 hour at ambient temperature using a cold press (CGYJ-100, Shijiazhuang Cangao High Frequency Machinery co. LTD, China). After cold pressing, pine glulam samples were preserved for 3 days before the test.

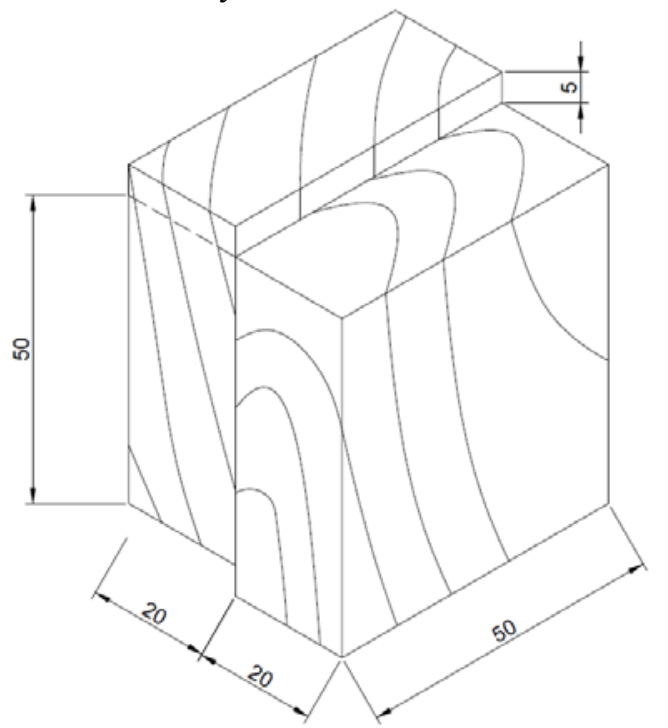

Figure 1. Diagram of test specimen for shear strength test.

\subsection{Method for the testing of glulam}

The bonding performance of resin was determined in accordance with the Chinese National Standard, GB/T 26899-2011 Structural Glued Laminated Timber. The dry and wet shear strength, wood failure percentage, total delamination percentage after cold and boiling water soak of glulam samples were measured. The glulam samples were treated under wet conditions of 24 $\mathrm{h}$ cold water soak and $4 \mathrm{~h}$ boiled water soak. A universal mechanical testing machine (AG-100KN-MO, Shimadzu Corporation, Japan) was used to perform the shear strength test.

\section{Results and discussions}

During the bonding process of glulam with adhesive, both press process parameters and adhesive characteristic parameters affect the bonding performance and production cost of glulam. In this study, pressure and press time as the press process parameters, amount of adhesive coating and dosage of curing agent as the adhesive characteristic parameters were selected as the influence factors.

\subsection{Impact of press process}




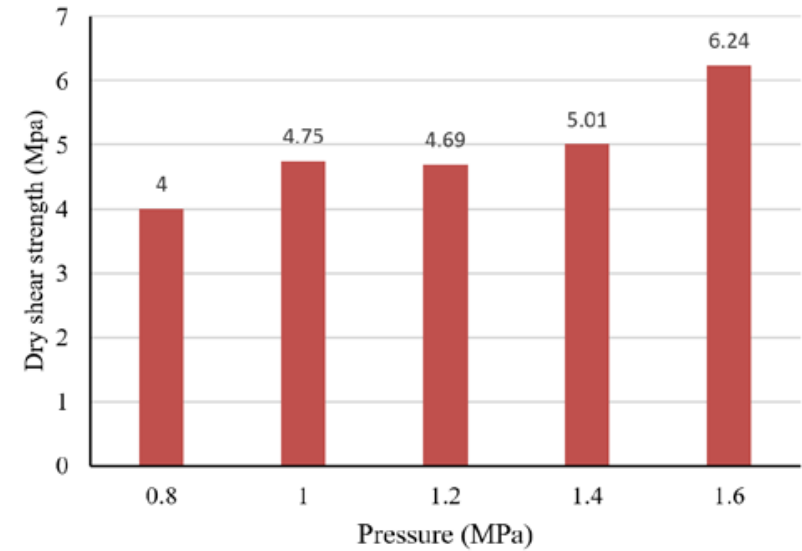

Figure 2. Effect of pressure on the dry shear strength of BRPF glulam

As shown in Fig. 2, under the same condition of press time, amount of adhesive coating and proportion of curing agent, the dry shear strength of BRPF glulam increased as raising the pressure during the press process. Higher pressure makes adhesion being easier to permeate into the microcellular structure of wood, which has more chance to generate bonding reaction with larger wood area, and then produce stronger adhesion. In all the experimental conditions, the wood failure percentage was $100 \%$, which shows that BRPF adhesive produced very good bonding with pine wood material.

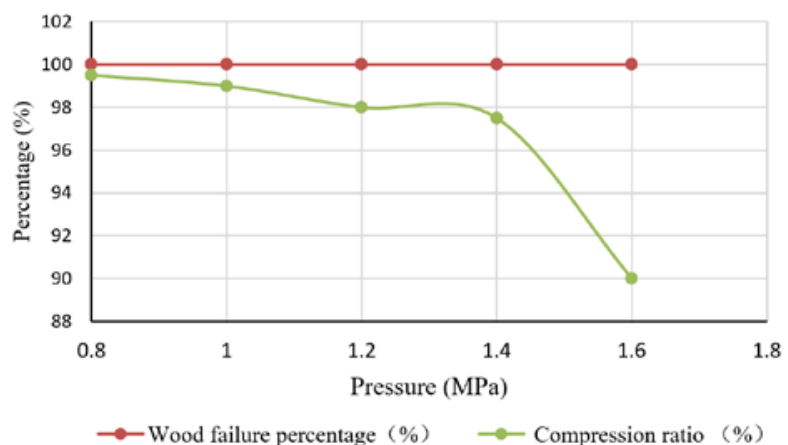

Figure 3. Effect of pressure on the bonding performance of BRPF glulam

Enough pressure is necessary for the good bonding performance, but overlarge pressure may produce high compression effect on the wood materials used in glulam, especially for the softwood. It can be seen from Fig. 3 that a pressure of larger than $1.4 \mathrm{MPa}$ has significant impact on the compression ratio of pine lamina with a value of $90 \%$.

A pressure of $1.4 \mathrm{MPa}$ was chosen comprehensively considering its impact on both dry shear strength and compression ratio.

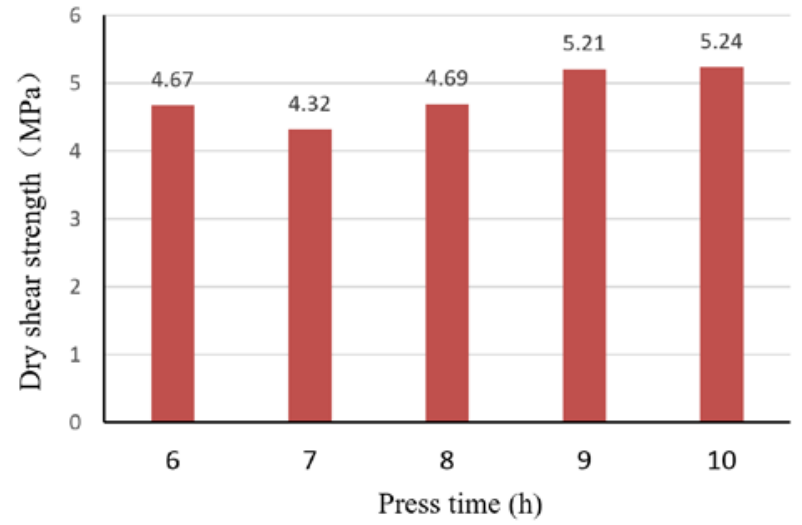

Figure 4. Effect of press time on the dry shear strength of BRPF glulam

Good strong adhesive between the adhesive and the wood is achieved by appropriate adhesive flow, penetration, wetting and curing, which need enough time to finish this process. Press time has distinct effect on the bonding strength of glulam. 4.67 $\mathrm{MPa}$ of dry shear strength was obtained for the sample when a press time of 6 hour was used. Afterwards, the dry shear strength of glulam samples decreased and then increased as extending the press time. A press time of 9 hour was selected for the bonding process parameter.

\subsection{Impact of adhesive and curing agent dosage}

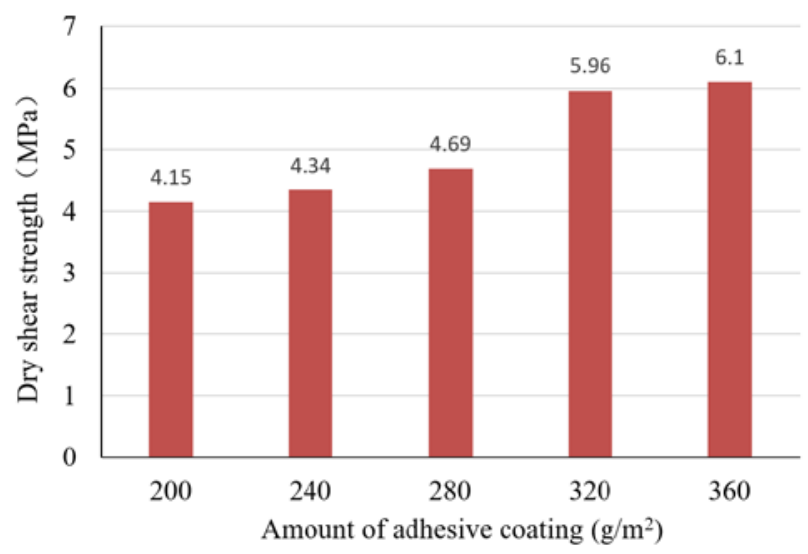

Figure 5. Effect of amount of adhesive coating on the dry shear strength of BRPF glulam

The amount of adhesive used for bonding the laminas affected the mechanical property of glulam. When the amount of adhesive coating increased from $200 \mathrm{~g} / \mathrm{m}^{2}$ to $360 \mathrm{~g} / \mathrm{m}^{2}$, the dry shear strength of samples also grew from 4.15 $\mathrm{MPa}$ to $6.1 \mathrm{MPa}$. However, the dry shear strength of glulam with $360 \mathrm{~g} / \mathrm{m}^{2}$ of adhesive were close to that of glulam with $320 \mathrm{~g} / \mathrm{m}^{2}$. Considering both strength and product cost, $320 \mathrm{~g} / \mathrm{m}^{2}$ is recommended during the bonding process of glulam. 


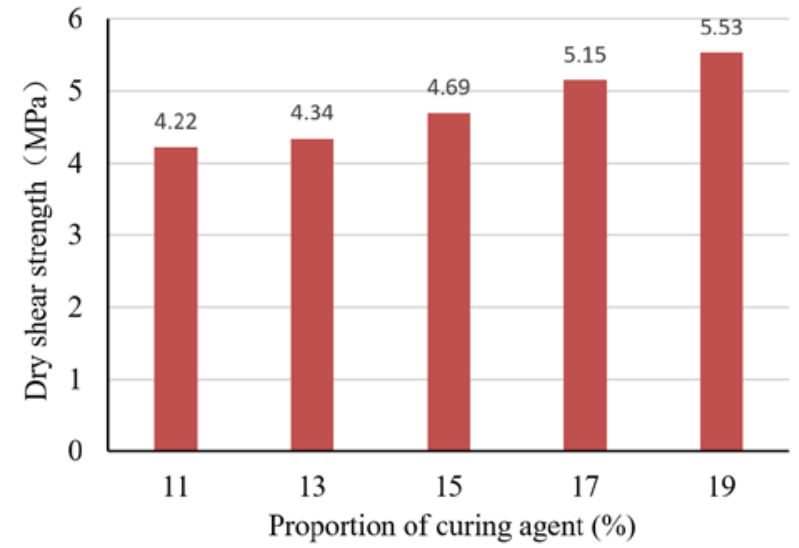

Figure 6. Effect of proportion of curing agent on the dry shear strength of BRPF glulam

Curing agent helps the micro-molecule of adhesive to form macro-molecular structure, and then generate good cross-linking and connection with wooden materials. Proper proportion of curing agent relative to adhesive produce a good bonding effect, but excess of curing agent will cost too much for the preparation of glulam. In this study, $17 \%$ of curing agent (polyformaldehyde) is recommended to use for the BRPF adhesive.

It can be concluded that the optimized process parameters for the cold-pressing adhesion of the bio-oil phenolic resin with pine wood were as follows: the coldpressing pressure $1.4 \mathrm{MPa}$, the cold-pressing time $9 \mathrm{~h}$, the amount of adhesive coating $320 \mathrm{~g} / \mathrm{m}^{2}$, and the proportion of curing agent (poly-formaldehyde) $17 \%$.

\subsection{Verification of optimal parameters}

A verification experiment was conducted to validate the optimal parameters. The mechanical properties of glulam using BRPF adhesive prepared under the optimal conditions are shown in Table 2.

Table 2. Verification experiment result of optimal parameters

\begin{tabular}{|c|c|c|c|c|}
\hline No. & 1 & 2 & 3 & Average \\
\hline $\begin{array}{c}\text { Dry shear strength } \\
\text { (MPa) }\end{array}$ & $\mathbf{6 . 1 1}$ & $\mathbf{5 . 9 2}$ & $\mathbf{5 . 5 5}$ & $\mathbf{5 . 8 6}$ \\
\hline $\begin{array}{c}\text { Wet shear strength } \\
\text { in cold water } \\
\text { (MPa) }\end{array}$ & $\mathbf{4 . 6 3}$ & $\mathbf{3 . 9 6}$ & $\mathbf{4 . 7 2}$ & $\mathbf{4 . 4 4}$ \\
\hline $\begin{array}{c}\text { Wet shear strength } \\
\text { in hot water } \\
\text { (MPa) }\end{array}$ & $\mathbf{3 . 6 4}$ & $\mathbf{3 . 2 1}$ & $\mathbf{3 . 1 4}$ & $\mathbf{3 . 3 3}$ \\
\hline $\begin{array}{c}\text { Total delamination } \\
\text { percentage in cold } \\
\text { water (\%) }\end{array}$ & $\mathbf{0}$ & $\mathbf{0}$ & $\mathbf{0}$ & $\mathbf{0 . 0 0}$ \\
\hline $\begin{array}{c}\text { Total delamination } \\
\text { percentage in hot } \\
\text { water (\%) }\end{array}$ & $\mathbf{0 . 7 5}$ & $\mathbf{0}$ & $\mathbf{1 . 2}$ & $\mathbf{0 . 6 5}$ \\
\hline
\end{tabular}

Dry shear strength of sample was $5.86 \mathrm{MPa}$, and this value decreased to $4.44 \mathrm{MPa}$ and $3.33 \mathrm{MPa}$, respectively after immersion treatment in cold water and hot water. A high percentage of wood failure was gained both under dry and wet condition for the glulam samples, shown in Figure 7. Delamination was not found for the glulam sample treated in cold water. The total delamination percentage in hot water was $0.65 \%$, which is well below the requirement of standard.

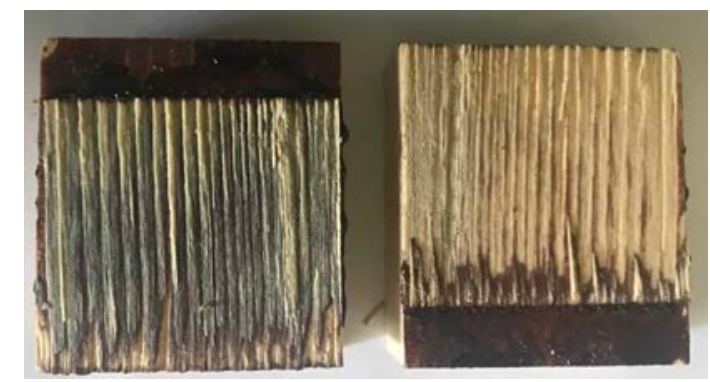

Figure 7. Shear failure surface of laminated wood

\section{Conclusions}

(1) Bio-oil phenolic resin was successfully used to bond the laminas to produce glulam, which has the potential as a novel bio-based structural adhesive.

(2) The optimized process parameters for the coldpressing adhesion of the bio-oil phenolic resin with pine wood were as follows: the cold-pressing pressure 1.4 $\mathrm{MPa}$, the cold-pressing time $9 \mathrm{~h}$, the amount of adhesive coating $320 \mathrm{~g} / \mathrm{m}^{2}$, and the proportion of curing agent (poly-formaldehyde) $17 \%$.

(3) The mechanical properties of laminated wood bonding with bio-oil phenolic resin under the optimized condition were as follows: wood failure percentage $100 \%$, dry shear strength $5.86 \mathrm{MPa}$, wet shear strength $4.44 \mathrm{MPa}$ in cold water and $3.33 \mathrm{MPa}$ in hot water, total delamination percentage in cold water $0 \%$, and total delamination percentage in hot water $0.65 \%$.

This work was supported by the Fundamental Research Funds for the Central Universities (No. 2017ZY39), Beijing Forestry University-National College Students' Innovation and Entrepreneurship Training Program (G201710022029), National Key Research and Development Program-sub Project (2017YFD0601205).

\section{References}

1. C. A. Issa, Z. Kmeid. Advanced wood engineering: glulam beams. Constr. Build Mater. 19, 99-106 (2005) 2. R. W. Caster, M. M. Gillem, J. T.Howel, Forest Prod J 23, $55(1973)$

3. N. Hori, K. Asai, A. Takemura, J Wood Sci, 54, 294 (2008)

4. M. Properzi, A. Pizzi, L. Uzielli, Holz Roh Werkst, 59, $413(2001)$

5. M. Dos Anjo Azambuja, A. Alves Dias. Mater. Res. 9, 287-291 (2006)

6. Z. Guo, W. Zhang, Z. Zhao, M. Guo. J. Appl. Polym. Sci. 120, 220-225 (2011) 
7. H. Sahin Kol, G. Özbay, S. Altun. BioRe. 4, 15451554 (2009)

8. D. Ohnesorge, K. Richter, G. Becker. Ann. For. Sci. 67, 601 (2010)

9. X. Ren, J. Gou, W. Wang, Q. Li, J. Chang, B. Li. BioRe. 8, 6481-6492 (2013)

10. X. Ren, H. Cai, H. Du, J. Chang. Polym. 9, 232 (2017) 